\title{
Use of aspirin for primary and secondary prevention of cardiovascular disease in diabetic patients in an ambulatory care setting in Spain
}

\author{
Antoni Sicras-Mainar*1, Ruth Navarro-Artieda ${ }^{\dagger 1}$, Javier Rejas-Gutiérrez ${ }^{\dagger 2}$, \\ Jaime Fernández-de-Bobadilla ${ }^{\dagger 2}$, Xavier Frías-Garrido ${ }^{\dagger 1}$ and Rafael Ruiz- \\ Riera $^{\dagger 1}$
}

Address: ${ }^{1}$ Badalona Serveis Assistencials SA, Badalona, Barcelona, Spain and ${ }^{2}$ Investigación de Resultados en Salud, Unidad Médica Pfizer, Madrid, Spain

Email: Antoni Sicras-Mainar* - asicras@bsa.gs; Ruth Navarro-Artieda - rnavarro.germanstrias@gencat.net; Javier Rejas-

Gutiérrez - javier.rejas@pfizer.com; Jaime Fernández-de-Bobadilla - jaime.fernandez@pfizer.com; Xavier Frías-Garrido - xfrias@bsa.gs; Rafael Ruiz-Riera - rruiz@bsa.gs

* Corresponding author †Equal contributors

Published: 17 October 2007

BMC Family Practice 2007, 8:60 doi:10.1186/147/-2296-8-60

This article is available from: http://www.biomedcentral.com/I47I-2296/8/60

(C) 2007 Sicras-Mainar et al; licensee BioMed Central Ltd.

This is an Open Access article distributed under the terms of the Creative Commons Attribution License (http://creativecommons.org/licenses/by/2.0), which permits unrestricted use, distribution, and reproduction in any medium, provided the original work is properly cited.
Received: 9 May 2007

Accepted: 17 October 2007

\begin{abstract}
Background: This study was conducted in order to determine the use of aspirin and to assess the achievement of therapeutic targets in diabetic patients according to primary (PP) or secondary prevention (SP).

Methods: This is a retrospective, observational study including patients $\geq 18$ years with diabetes mellitus followed in four primary care centers. Measurements included demographics, use of aspirin and/or anticoagulant drugs, co-morbidities, clinical parameters and proportion of patient at therapeutic target (TT). Descriptive statistics, chi-square test and logistic regression model were used for significance.

Results: A total of 4, I 40 patients were analyzed, $79.1 \%$ (95\% confidence intervals [Cl]: 77.780.5\%) in PP and 20.9\% (95\% Cl: 18.2-23.7\%) in SP. Mean age was 64.I (I3.8) years, and 49.3\% of patient were men (PP: 46.3, SP: 60.7, $\mathrm{p}=0.00 \mathrm{I})$. Aspirin was prescribed routinely in $20.8 \%(95 \%$ Cl: 19.4-22.2\%) in PP and 60.8\% (95\% Cl: 57.6-64.0\%) in SP. Proportion of patient at TT was 48.0\% for blood pressure and $59.8 \%$ for cholesterol. Use of aspirin was associated to increased age [OR $=\mathrm{I} .0 \mathrm{I}(95 \% \mathrm{Cl}: \mathrm{I} .00-\mathrm{I} .02) ; \mathrm{p}=0.0 \mathrm{I} \mathrm{I}]$, cardiovascular-risk factors [OR = I.I4 (95\% Cl: I.03-I.27); $\mathrm{p}=0.0 \mathrm{I} 3]$, LDL-C [OR = I.42 (95\% Cl: I.06-I.88); $\mathrm{p}=0.0 \mathrm{I} 7]$ and higher glycated hemoglobin [OR $=I .5 \mathrm{I}(95 \% \mathrm{Cl}:$ I.22-I.89); $\mathrm{P}=0.000]$ were covariates associated to the use of aspirin in PP.
\end{abstract}

Conclusion: Treatment with aspirin is underused for PP in patients with diabetes mellitus in Primary Care. Achievement of TT should be improved. 


\section{Background}

Arterial hypertension, hypercholesterolemia, smoking, obesity, lack of physical activity and diabetes mellitus represent the main modifiable risk factors for the occurrence of cardiovascular diseases in developed countries [1]. Patients with diabetes mellitus have a cardiovascular risk two to four times higher than the general population. Complications attributable to atherosclerosis are responsible for $70-80 \%$ of all deaths in diabetic patients and account for more than $75 \%$ of all hospital admissions, causing high rates of disability and health resource utilization [2]. There is currently a clear trend to an increased prevalence, due both to the progressive aging of the population and to the increased frequency of sedentary habits and obesity.

This situation makes institution of drug measures for primary and secondary prevention in patients with cardiovascular disease (CVD) a primary objective. The American Diabetes Association [3] (ADA) recommends use of antiaggregants (low-dose acetyl salicylic acid [ASA], 75$325 \mathrm{mg}$ /day) in all diabetic patients with established CVD (secondary prevention) and in those with no CVD who have a high risk of cardiovascular events (primary prevention) or are over 40 years of age, provided there is no documented contraindication, such as allergy to salicylates, bleeding risk, anticoagulant therapy, recent gastrointestinal bleeding, active liver disease, or the age (to prevent Reye syndrome). These recommendations are based on three studies (ETDRS [4], HOT [5], and the Physicians' Health Study [6] showing that this treatment decreases the incidence of myocardial infarction in people with diabetes. Two of these studies are included in the meta-analysis of the US Preventive Services Task Force [7], which confirmed the decrease in the incidence of myocardial infarction, but found no significant differences in mortality reduction. In this regard, the American Heart Association [8] and the results reported by several meta-analyses $[9,10]$ recommend preventive treatment with ASA in people with a 10 -year risk higher than $10 \%$. Despite the fact that various Spanish scientific societies (such as the Catalan Societies of Diabetes, Neurology, Cardiology, Family and Community Medicine, etc.) also support the start of ASA therapy as one of the main cost-effective measures, the scant evidence reported in our setting [11-13] suggest that it is underused. Additional studies conducted in other countries further support the consistency of these results [14-18].

The rationale of the study was to review to what extent these recommendations/guidelines, which are evidence base medicine, are implemented in real world standard condition of care in a primary care setting in Spain. Then, the purpose of this study was to determine the use of ASA for cardiovascular prevention in patients with diabetes mellitus at several health care centers under standard clinical practice conditions, and to ascertain the extent to which some therapeutic control objectives are achieved in primary care setting.

\section{Methods \\ Study design and data extraction}

A retrospective, observational study was conducted based on the medical records of patients monitored on an outpatient basis and under standard clinical practice conditions. The study population consisted of people of either sex attending four primary care centers managed by Badalona Serveis Assistencials SA. All patients older than 18 years diagnosed of diabetes mellitus according to the criteria established by the ADA [3] and seen at the center over the past two years (January 2004 and December 2005) were enrolled in the study. Patients with a doubtful diagnosis and patients in whom onset of the disease had occurred less than 3 months before were excluded from the study $(\mathrm{n}=186)$.

Variables recorded included age, sex, social security status (active worker, retired), primary care center identification, time (months) since initial diagnosis of the disease, number of annual visits attended according to the protocol or clinical practice guideline for cardiovascular risk of the centers, number of cardiovascular risk factors, treatment prescribed, and regular use of ASA or other oral antiaggregant and/or anticoagulant drugs (including triflusal, clopidogrel, ticlopidine, warfarin and acenocoumarol). Aspirin regular use by a patient was established when a physician prescribed aspirin for more than 8 months per year. Clinical diagnoses or comorbidities associated to diabetes mellitus were obtained from the International Classification of Primary Care (ICPC-2) [19]. Non-repeated events seen in the population considered included arterial hypertension (K86, K87), hypercholesterolemia (T93: partial), active smoker (P17), obesity (T82); presence of CVD: ischemic heart disease (K74: cardiac ischemia with angina, K75: acute myocardial infarction, K76: coronary ischemia), cerebrovascular accident (K90, K91: transient cerebral ischemia), and peripheral artery disease (K92: intermittent claudicating, Raynaud syndrome, arterial stenosis or embolism); and other comorbidities: congestive heart failure (K77), renal failure (U99), liver failure (D97), chronic obstructive pulmonary disease (R95: chronic airflow obstruction), depressive syndrome (P76), and benign prostate hypertrophy (Y87). Information was obtained from the computerized clinical records. Legal regulations on data confidentiality were complied with at all times.

\section{Measurements}

The clinical parameters measured included the cardiovascular risk index (Framingham calculation adapted for pri- 
mary care), body mass index (BMI $<29, \mathrm{~kg} / \mathrm{m} 2)$, systolic (SBP, $\mathrm{mmHg}$ ) and diastolic blood pressure (DBP, $\mathrm{mmHg}$ ), total cholesterol $(\mathrm{mg} / \mathrm{dL})$, low density lipoprotein cholesterol fraction (LDL-C, obtained by the Friedewald formula [20]), high density lipoprotein cholesterol fraction (HDL-C), and glycated hemoglobin (HbA1c). Some of the established recommendations $[3,21]$ for blood pressure (SBP/DBP $<130 / 80 \mathrm{mmHg}$ ), and LDL-C $(<100 \mathrm{mg} / \mathrm{dL}$ ), see Table 1 . Besides, we followed modified criterion to adapt them to a real clinical practice conditions: glycated hemoglobin $(<6.5 \%)$, total cholesterol $(<200 \mathrm{mg} / \mathrm{dL})$ and body mass index $(\mathrm{BMI}<29, \mathrm{~kg} / \mathrm{m} 2)$, they were considered as adequate follow-up or target objectives.

The last measurement obtained during 2005 was considered in all cases.

\section{Statistical methods}

Data depuration and database refining from mistake or wrong records were carried out in order to obtain good data to run statistical analyses. Personal data were blinded before analysis in order to guarantee proper anonymity of patient's data in accordance with present local regulations with data management and processing. Descriptive statistics (mean, standard deviation and 95\% confidence interval) and testing of Gaussian distribution by means of the Kolmogorov-Smirnov test were performed for descriptive purposes. Bivariate analysis using t-test, Man-Whitney test or $\mathrm{Chi}^{2}$, as appropriated, were applied to compare main patients' characteristics between primary and secondary prevention. To test for homogeneity of centers, we used an analysis of variance (ANOVA) or $\mathrm{Chi}^{2}$ tests.

Multiple logistic regression models (enter step procedure) were carried out in the total sample, and in the subgroups according with type of prevention. The use of ASA was the dependent variable, and all significant variables observed in the bivariate analysis were incorporated into the models as independent factors. These included mean age (years), sex (male), active workers, time since disease onset (months), number of visits in the annual cardiovascular risk protocol, presence of a cardiovascular history, hypercholesterolemia and active smoking, and achievement of the therapeutic control objectives (dichotomic variables): blood pressure $(<130 / 80 \mathrm{mmHg})$, total cholesterol $(<200 \mathrm{mg} / \mathrm{dL})$, LDL-C $(<100 \mathrm{mg} / \mathrm{dL})$ and HbA1c $(<6.5 \%)$. SPSS version 14.0 for Windows software was used, and a value of $\mathrm{p}<0.05$ was established as the significant level.

\section{Ethical considerations}

The World Medical Association has developed the Declaration of Helsinki as a statement of ethical principles to provide guidance to physicians and other participants in medical research involving human subjects. The authors show that in the elaboration of the study the basic principles for all medical research and the confidentiality of the data have been respected marked by the law.

\section{Results}

The number of patients with established diagnosis of diabetes mellitus was 4,140 (crude prevalence: $6.4 \%$ of the total population), $79.1 \%$ (CI: $77.7-80.5 \%$ ) in primary prevention and $20.9 \%$ (CI: $18.2-23.7 \%$ ) in secondary prevention. Overall, by December 2004, $14.6 \%$ of patients followed diet therapy, while $55.2 \%$ were receiving oral antidiabetics, $9.7 \%$ oral antidiabetics plus insulin, and $20.5 \%$ insulin alone.

Table 2 shows the general characteristics of the studied series, the cardiovascular history, and the therapeutic control objectives in patients with diabetes mellitus by primary care center. No differences were seen between

Table I: Therapeutic targets in prevention and treatment of cardiovascular disease in diabetes.

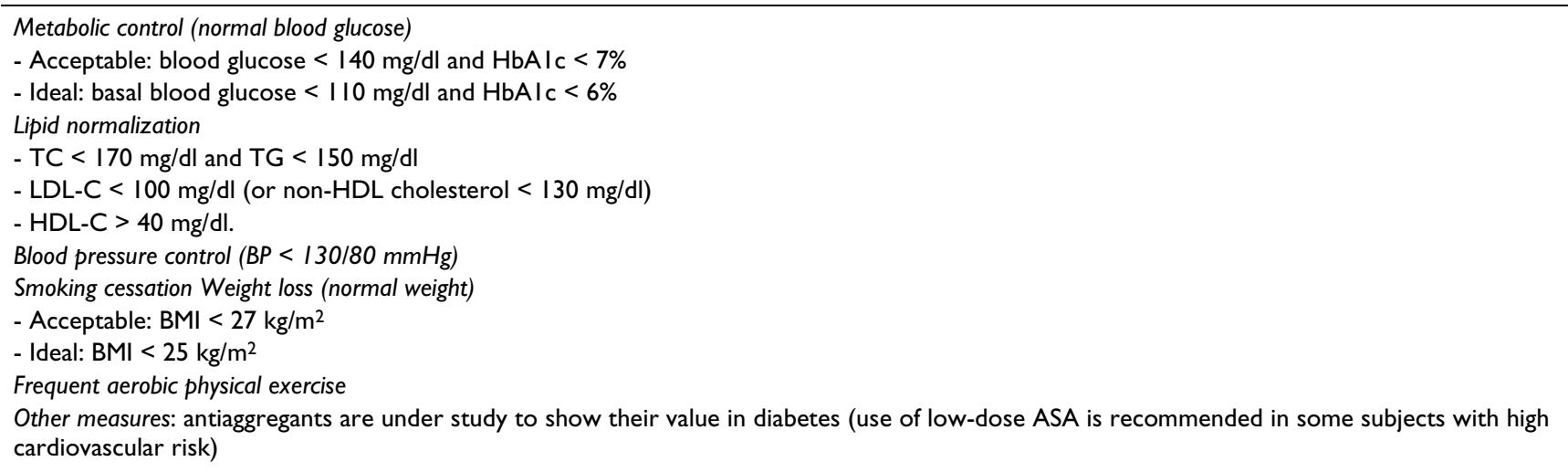

HbAI c: glycated hemoglobin; LDL-C: low density lipoprotein cholesterol; HDL-C: high density lipoprotein cholesterol; BMI: body mass index; ASA: acetyl salicylic acid. Source: "Grupo de Trabajo Diabetes mellitus. Diabetes mellitus y riesgo cardiovascular. Recomendaciones del Grupo de Trabajo Diabetes Mellitus y Enfermedad Cardiovascular de la Sociedad Española de Diabetes. Clin Invest Arterioscl 2004;16:74-8". 
centers in cardiovascular events (range, 20.0-22.2\%) or cardiovascular history (except for arterial hypertension; range, 49.4-55.8\%; $\mathrm{p}=0.002$ ), and the percentages seen for hypercholesterolemia, active smoking, and obesity showed a certain homogeneity. The greatest variability between centers was seen in percentage of use of ASA (ranging from 20.0 to 35.3\%; p < 0.001), mean patient age (ranging from 62.2 [14.2] to 65.5 [13.5]; p < 0.001), and particularly achievement of therapeutic target objectives. Thus, target blood pressure $(<130 / 80 \mathrm{mmHg})$ was achieved in $37.4-57.6 \%$ of patients $(\mathrm{p}=0.002)$; target total cholesterol $(<200 \mathrm{mg} / \mathrm{dL})$ in $42.1-50.7 \%$ of patients $(\mathrm{p}<0.001)$; and target LDL-C $(<100 \mathrm{mg} / \mathrm{dL})$ in $13.5 \%$ to $21.7 \%$ of cases $(p=0.000)$.

Distribution of the study variables by type of prevention (primary or secondary) is shown in Table 3. Mean patient age was 64.1 (13.8) years, and the values for patients in primary and secondary prevention were 62.3 (14.1) years and $70.9(10.0)$ years respectively $(\mathrm{p}=0.000)$. There was a $2.8 \%$ primary prevention (PP) patients aged less than 30 years, as compared to none in the secondary prevention (SP) group. Males accounted for $49.3 \%$ of the population (PP: 46.3; SP: 60.7; $\mathrm{p}=0.000$ ). Of all patients, $29.2 \%$ (CI: $27.8 \%-30.6 \%$ ) was prescribed in ASA, 20.8\% (CI: 19.4\%-22.2\%) in PP and 60.8\% (CI: 57.6\%-64.0\% in SP; $10.5 \%$ of patients were routinely prescribed some other oral antiaggregant or anticoagulant (PP: 5.1\%; SP: 30.9\%; $\mathrm{p}=0.000)$. In SP, blood pressure $(55.9 \%)$ and hypercholesterolemia $(47.5 \%)$ were most prevalent in the history, and the conditions where better therapeutic control objectives were achieved (48.0\% and 59.8\% respectively; $\mathrm{p}=$ $0.000)$. The distribution of the number of cardiovascular risk factors associated to patients with diabetes mellitus (primary or secondary prevention) is shown in Figure 1. It should be noted that most diabetic patients with no presence of CVD have $2(35.8 \%)$ or $3(29.5 \%)$ cardiovascular risk factors.

The final regression logistic model (Table 4) showed that patients with controlled-total-cholesterol were significantly associated to the use of ASA in secondary prevention; $\mathrm{OR}=1.50 ; \mathrm{CI}: 1.02-2.21 ; \mathrm{p}=0.039$. However, patients on primary prevention, were more likely to use ASA when age increases $(\mathrm{OR}=1.01$; IC: $1.00-1.02 ; \mathrm{p}=$ $0.011)$, show a higher number of cardiovascular risk factors $(\mathrm{OR}=1.14 ; \mathrm{CI}: 1.03-1.27 ; \mathrm{p}=0.013)$, achieve therapeutic LDL-C targets $(\mathrm{OR}=1.42 ; \mathrm{CI}: 1.06-1.88 ; \mathrm{p}=$ $0.017)$, and get a poor metabolic control of glycated hemoglobin $(\mathrm{OR}=1.51 ; \mathrm{CI}: 1.22-1.89 ; \mathrm{p}=0.000)$.

\section{Discussion}

Studies on the use of acetyl salicylic acid for primary and prevention of cardiovascular disease in adult diabetic patients and their adherence to the recommendations in clinical practice guidelines are heterogeneous in character [11-18], [22-24]. It is important to note that the different methods used for measuring some variables in the reviewed studies make comparisons difficult and requires caution when considering the external validity of results. However, such limitations do not invalidate the current knowledge obtained from such patients, resulting from observations under standard clinical practice conditions in an outpatient setting.

Table 2: General distribution of patients with diabetes mellitus by primary care center (PCC).

\begin{tabular}{|c|c|c|c|c|c|}
\hline Variables & PCC-I n = 978 & PCC-2 $n=1,486$ & PCC-3 n = 902 & PCC-4 n = 774 & $P$ \\
\hline CVD (events, \%) & 22.2 & 20.7 & 20.0 & 21.1 & ns \\
\hline Use of ASA (\%) & 29.1 & 35.3 & 20.0 & 28.2 & 0.000 \\
\hline Sex (males, \%) & 46.9 & 51.5 & 46.8 & 50.9 & 0.041 \\
\hline Mean age (SD), years & $62.2(14.2)$ & $64.1(13.5)$ & $65.5(13.5)$ & $64.9(13.9)$ & 0.000 \\
\hline \multicolumn{6}{|l|}{ CV history } \\
\hline Hypertension & 49.4 & 51.2 & 55.8 & 50.0 & 0.002 \\
\hline Hypercholesterolemia & 35.8 & 39.5 & 37.7 & 36.2 & ns \\
\hline Active smoking & 21.6 & 17.7 & 18.3 & 17.2 & ns \\
\hline Obesity (BMI < 29) & 48.5 & 46.9 & 46.4 & 43.9 & ns \\
\hline \multicolumn{6}{|l|}{ Therapeutic targets } \\
\hline $\mathrm{BP}(<130 / 80 \mathrm{mmHg})$ & 49.6 & 37.4 & 50.1 & 57.6 & 0.002 \\
\hline Total cholesterol (<200 mg/dL) & 50.6 & 50.7 & 41.1 & 45.0 & 0.000 \\
\hline LDL-C (<100 mg/dL) & 20.6 & 21.7 & 13.5 & I7.I & 0.000 \\
\hline Glycated HbAlc $(<6.5 \%)$ & 33.3 & 34.4 & 32.0 & 33.6 & ns \\
\hline
\end{tabular}

Values are given as percentage or mean (SD: standard deviation); p: statistical significance; CVD: cardiovascular disease; ASA: acetyl salicylic acid; $\mathrm{CV}$ : cardiovascular; BMI: body mass index; BP: blood pressure (mmHg); LDL-C: low density lipoprotein cholesterol (mg/dL); Hb: hemoglobin. 


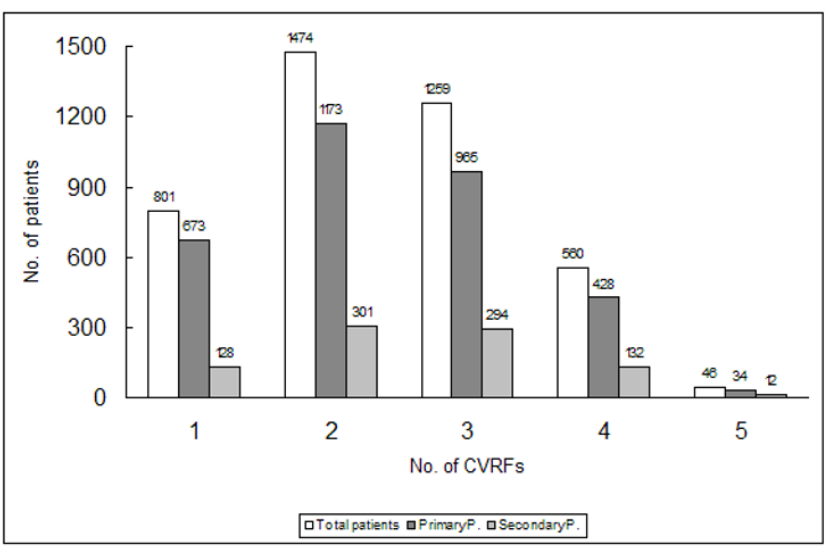

Figure I

Distribution of the number of cardiovascular risk factors (CVRFs) associated to patients in primary or secondary prevention.

Although explanations may arise when an attempt is made to analyze the general characteristics of patients based on their clinical history (direct correlation between age and arterial hypertension), some degree of uncertainty is generally shown in the care process [25], that may possibly be influenced by the health status of the population and the different existing clinical practice approaches, randomly distributed among the primary care centers reviewed.

In our study, ASA was prescribed by $29.2 \%$ of diabetic patients (CI: 27.8-30.6\%). However, the proportion increased to $39.4 \%$ when use of other antiaggregant or anticoagulant drugs was considered. It should be stressed that in SP the proportion reaches $91.7 \%$ of diabetic patients (as compared to $25.9 \%$ in PP). Diabetic patients with CVD are mostly older men with a longer time since disease onset and a higher number of associated comorbidities (arterial hypertension and hypercholesterolemia). Moreover, this group has been subject to a more extensive follow-up in the scheduled control visits, and has shown a better achievement of therapeutic goals (except for glycated hemoglobin). It should be noted that a history of CVD clearly suggests to the physician and patient the need for treatment, while the opposite occurs when there is no such history. While, by definition, diabetic patients with no history of cardiovascular disease are considered "primary prevention" patients, the risk for diabetics with no coronary history is in some studies similar to the risk of post-myocardial infarction non-diabetic patients [26]. This fact has caused the control objectives for risk factors in the diabetic population established by scientific associations to be similar to those recommended for secondary prevention patients. These observations demonstrate the potential relationship between monitoring and a better metabolic control [27,28]. An increased awareness and a more decided action by the family physician when faced with a diabetic patient in secondary prevention may also exist [17].

Use of ASA for primary prevention in patients with diabetes mellitus is considered in elderly diabetics with several cardiovascular risk factors, LDL-C therapeutic objectives, and poor metabolic control of glycated hemoglobin. In these patients (with no cardiovascular event), both ASA use and achievement of control objectives can still be improved, particularly taking into account that most primary prevention patients meet criteria for antiaggregant therapy $[3,11,22]$. Patients and/or healthcare professionals may possibly see regular use of ASA as a non-relevant or second level treatment, as discussed by some authors $[16,17]$ and demonstrated in our study. This suggests that patients with diabetes are not treated as a function of risk, but of the presence of CVD and the degree of metabolic control achieved.

The results obtained, when compared to national studies [11-13], generally show some differences in the characteristics of the diabetic patients studied, possibly attributable to the population profile used, but the rates of ASA underused are similar. Other consulted series show incremental percentages over the years, but lower than desirable values [14-17,24]. Therapeutic control objectives were achieved in similar or slightly higher percentages as compared to other series reviewed $[28,29]$. It is paradoxical that while various renowned scientific associations $[3,8,21]$ recommend use of ASA or other antiaggregants for primary prevention in diabetic patients older than 40 years, or patients under 21 years of age having some associated risk factor, such advice is not followed in clinical practice. But the most important thing is that a CVD (often angina or infarction) is not prevented [11]. In this regard, the cost of prevention of a cardiovascular event with ASA treatment would be much lower than the costs resulting from hospitalization and sequels, not to speak of the social and personal burden for these patients $[2,11]$.

The efficacy of ASA in clinical trials $[4-9,30]$ contrasts with various pathophysiological studies that would explain why patients with diabetes mellitus may be more resistant to the potential benefits of the drug. Some authors postulate that response to preventive ASA treatment could be different in diabetic patients for several reasons [31]. These would include the fact that diabetes may be a form of resistance to ASA or to low doses of ASA; platelets of these patients could be activated by various mechanisms that would lead to thrombosis, or also because the inflammatory stimuli present in diabetic patients could induce a cyclooxygenase-2 enzyme poorly sensitive to ASA. It has also been postulated that hyperglycemia could generate a 
Table 3: General characteristics of patients with diabetes mellitus by type of cardiovascular prevention (primary, secondary).

\begin{tabular}{|c|c|c|c|c|}
\hline Characteristics & Primary $n=3,273$ & Secondary $\mathrm{n}=867$ & Total $n=4,140$ & $\mathrm{P}$ \\
\hline Mean age (SD), years & $62.3(14.1)$ & $70.9(10.0)$ & $64.1(13.8)$ & 0.000 \\
\hline Sex (males, \%) & 46.3 & 60.7 & 49.3 & 0.000 \\
\hline SS status (active, \%) & 37.4 & 11.2 & 31.9 & 0.000 \\
\hline Time since diagnosis (SD), months & $43.2(37.5)$ & $52.6(49.1)$ & $45.2(40.4)$ & 0.000 \\
\hline Follow-up per protocol (SD), visits & $3.9(3.2)$ & $4.4(3.5)$ & $4.0(3.3)$ & 0.000 \\
\hline \multicolumn{5}{|l|}{ CV history } \\
\hline Arterial hypertension & 49.2 & 55.9 & 50.6 & 0.002 \\
\hline Hypercholesterolemia & 34.9 & 47.5 & 37.6 & 0.001 \\
\hline Active smoking & 19.3 & 16.0 & 18.9 & 0.026 \\
\hline Obesity (BMI < 29) & 47.0 & 45.2 & 46.6 & ns \\
\hline \multicolumn{5}{|l|}{ Other co-morbidities } \\
\hline Heart failure & 2.4 & 8.1 & 3.6 & 0.000 \\
\hline Renal failure & 1.0 & 3.2 & 1.5 & 0.000 \\
\hline Liver failure & 2.8 & 3.9 & 3.0 & ns \\
\hline COPD & 4.8 & 12.9 & 6.5 & 0.000 \\
\hline Depressive syndrome & 14.2 & 14.6 & 14.3 & ns \\
\hline Prostatic hypertrophy & 4.3 & II.I & 5.7 & 0.000 \\
\hline \multicolumn{5}{|l|}{ Treatment } \\
\hline Acetyl salicylic acid & 20.8 & 60.8 & 29.2 & \\
\hline Other antiaggregants, OACs & 5.1 & 30.9 & 10.5 & 0.000 \\
\hline \multicolumn{5}{|l|}{ Clinical parameters } \\
\hline Body mass index (SD) & $30.3(5.3)$ & $29.9(4.9)$ & $30.2(5.2)$ & ns \\
\hline Systolic blood pressure (SD) & $135.3(17.2)$ & I35.4 (I7.9) & $135.4(17.4)$ & ns \\
\hline Diastolic blood pressure (SD) & $78.1(9.4)$ & $75.7(9.0)$ & $77.5(9.3)$ & 0.000 \\
\hline Total cholesterol (SD) & $206.9(41.3)$ & $192.9(39.9)$ & $203.9(41.4)$ & 0.000 \\
\hline LDL-C (SD) & $133.7(35.4)$ & $123.7(35.5)$ & $131.6(35.6)$ & 0.000 \\
\hline Glycated hemoglobin Alc (SD) & $7.2(1.5)$ & $7.4(1.4)$ & $7.3(1.5)$ & 0.014 \\
\hline CVR index (SD) & $21.1(9.1)$ & $25.2(9.9)$ & $22.1(9.3)$ & 0.000 \\
\hline \multicolumn{5}{|l|}{ Therapeutic targets } \\
\hline $\mathrm{BP}(<130 / 80 \mathrm{mmHg})$ & 46.1 & 48.0 & 46.5 & ns \\
\hline Total cholesterol $(<200 \mathrm{mg} / \mathrm{dL})$ & 44.1 & 59.8 & 47.5 & 0.000 \\
\hline LDL-C $(<100 \mathrm{mg} / \mathrm{dL})$ & 16.5 & 26.9 & 18.7 & 0.000 \\
\hline Glycated hemoglobin Alc (<6.5\%) & 35.2 & 27.2 & 33.4 & 0.001 \\
\hline
\end{tabular}

Values are given as percentage or mean (SD: standard deviation); p: statistical significance; SS: social security; CV: cardiovascular; OACs: oral anticoagulants; CVR: cardiovascular risk; BP: blood pressure ( $\mathrm{mmHg}$ ); LDL-C: low density lipoprotein cholesterol (mg/dL); COPD: chronic obstructive pulmonary disease.

significant amount of endoperoxides and thromboxan that would counteract the action of cyclooxygenases [32].

Some limitations of the study require caution in the generalization of the results. Such limitations include the retrospective design of the study, the lack of clinical results in coordination with other care levels (care continuum), and the reasons given for contraindication or intolerance to the drugs, and the lack of measure of ASA with medicinal products excluded from or not financed by the National Health System. The study sample may not be representative of the general primary care population in Spain. However, our results should be interpreted with caution, as further research supporting these results should be conducted in larger patient populations under standard clinical practice conditions. Moreover, the potential specific contraindications for ASA therapy could not be established in our study.

However, the organizational model and clinical action protocols [31] of centers such as the ones participating in the study are very similar, and we agree with several authors $[11,12,14]$ on the need that scientific associations and the healthcare administration design approaches aimed at increasing information and training of healthcare personnel in effective cardiovascular prevention measures, particularly in patients who have not developed any cardiovascular event. The results obtained should be 
Table 4: Correction of general and control variables associated to use of acetyl salicylic acid in primary and secondary prevention.

\begin{tabular}{|c|c|c|c|c|c|c|c|c|c|}
\hline \multirow{2}{*}{$\begin{array}{l}\text { Correction of logistic model } \\
\text { Variables }\end{array}$} & \multicolumn{3}{|c|}{ Primary prevention $n=3,273$} & \multicolumn{3}{|c|}{ Secondary prevention $\mathrm{n}=867$} & \multicolumn{3}{|c|}{ Total $n=4,140$} \\
\hline & OR & $P$ & $\mathrm{Cl}$ & OR & $P$ & $\mathrm{Cl}$ & OR & $P$ & $\mathrm{Cl}$ \\
\hline Age & 1.01 & 0.011 & $1.00-1.02$ & 0.98 & ns & - & 1.02 & 0.000 & $1.01-1.03$ \\
\hline Sex (males) & 0.98 & ns & - & 1.04 & ns & - & 0.80 & 0.006 & $0.68-0.94$ \\
\hline Number of CVRFs & 1.14 & 0.013 & $1.03-1.27$ & 1.03 & ns & - & 1.16 & 0.001 & $1.06-1.26$ \\
\hline Total cholesterol & 0.89 & ns & - & 1.50 & 0.039 & $1.02-2.21$ & 1.30 & 0.005 & $1.08-1.55$ \\
\hline LDL-C & 1.42 & 0.017 & $1.06-1.88$ & 0.83 & ns & - & 1.29 & 0.012 & $1.04-1.62$ \\
\hline Glycated HbAlc & 1.51 & 0.000 & $1.22-1.89$ & 1.07 & ns & - & 1.47 & 0.000 & $1.18-1.79$ \\
\hline
\end{tabular}

CVRFs: cardiovascular risk factors; LDL-C: low density lipoprotein cholesterol; OR: odds ratio adjusted by use of acetyl salicylic acid; CI: $95 \%$ confidence intervals. Control values incorporated into the final model: total cholesterol ( $<200 \mathrm{mg} / \mathrm{dL}), \mathrm{LDL}-\mathrm{C}(<100 \mathrm{mg} / \mathrm{dL})$, and glycated hemoglobin Alc (<6.5\%), p: statistical significance

of use when considering, based on the available evidence $[3,33]$, whether treatment should be started with ASA or other antiaggregant, when indicated, as it seems obvious that treatment with low-dose ASA is one of the most favorable cost-effective measures in cardiovascular prevention in diabetic patients $[3,22,34-37]$. Future research in diabetic patients should explore monitoring of preventive measures, effectiveness of the optimum recommended doses [38], or the specific reasons for poor patient compliance.

\section{Conclusion}

In our study treatment with ASA was underused for primary cardiovascular prevention in patients with diabetes mellitus. Achievement of the established therapeutic objectives should be improved. New representative studies under standard clinical practice conditions would be required.

\section{Competing interests}

The author(s) declare that they have no competing interests.

\section{Authors' contributions}

Each author participated sufficiently in the work to take public responsibility for appropriate portions of the content. All authors read and approved the final manuscript. ASM: conceived of the study, and participated in its design and coordination.

\section{Acknowledgements}

Authors wish to thank to all different professionals working in the participating primary care centers, as their daily collaboration made possible this study.

\section{References}

I. Mudaliar S: Intense management of diabetes mellitus: role of glucose control and antiplatelet agents. J Clin Pharmacol 2004, 44:4|4-22

2. Nobles-James C, James EA, Sowers JR: revention of cardiovascular complications of diabetes mellitus by aspirin. Cardiovasc Drug Rev 2004, 22:2 I5-26.
3. American Diabetes Association: Aspirin therapy in diabetes. Diabetes Care 2004, 27:S72-S3.

4. ETDRS Investigators: Aspirin effects on mortality and morbidity in patients with diabetes mellitus. Early Treatment Diabetic Retinopathy Study report I4. JAMA 1992, 268:1292-300.

5. Hansson L, Zanchetti A, Carruthers SG, Dahlof B, Elmfeldt D, Julius $\mathrm{S}$, Menard J, Rahn KH, Wedel $\mathrm{H}$, Westerling S: Effects of intensive blood-pressure lowering and low-dose aspirin in patients with hypertension: principal results of the Hypertension Optimal Treatment (HOT) randomised trial. HOT Study Group. Lancet 1998, 35 I:1755-62.

6. Steering Committee of the Physicians' Health Study Research Group: Final report on the aspirin component of the ongoing Physicians' Health Study. N Engl J Med 1989, 321:129-35.

7. Hayden M, Pignone M, Phillips C, Mulrow C: Aspirin for the primary prevention of cardiovascular events: a summary of the evidence for the U.S. Preventive Services Task Force. Ann Intern Med 2002, 136:161-72.

8. Pearson TA, Blair SN, Daniels SR, Eckel RH, Fair JM, Fortmann SP, Franklin BA, Goldstein LB, Greenland P, Grundy SM, Hong Y, Miller $\mathrm{NH}$, Lauer RM, Ockene IS, Sacco RL, Sallis JF Jr, Smith SC Jr, Stone NJ, Taubert KA: AHA Guidelines for Primary Prevention of Cardiovascular Disease and Stroke: 2002 update: Consensus Panel Guide to Comprehensive Risk Reduction for Adult Patients Without Coronary or Other Atherosclerotic Vascular Diseases. American Heart Association Science Advisory and Coordinating Committee. Circulation 2002, 106:388-9|.

9. Sanmuganathan PS, Ghahramani P, Jackson PR, Wallis EJ, Ramsay LE: Aspirin for primary prevention of coronary heart disease: safety and absolute benefit related to coronary risk derived from meta-analysis of randomised trials. Heart 200I, 85:265-7I.

10. Pueyo G, Elosua R, Marrugat J: Metaanálisis de la evidencia científica sobre la utilidad de la toma esporádica de ácido acetilsalicílico en la prevención de enfermedad coronaria. Med Clin (Barc) 2002, I 8:166-9.

II. López J, Escudero S, González AM, Mencía A, García LE, Morán B: Empleo de antiagregantes en la prevención primaria y secundaria cardiovascular del diabético en el medio urbano y rural del área de León. Aten Primaria 2003, 31:361-5.

12. Esmatjes E, Castell C, Franch J, Puigoriol E, Hernáez R: Consumo de ácido acetilsalicílico en pacientes con diabetes mellitus. Med Clin (Barc) 2004, I 22:96-8.

13. de Abajo FJ, Garcia Rodriguez LA: Consumo de ácido acetilsalicílico en pacientes con diabetes mellitus. Med Clin (Barc) 2004, 123:236.

14. Nguyen KX, Marinac JS, Sun C: Aspirin for primary prevention in patients with diabetes mellitus. Fam Med 2005, 37: I I 2-7.

15. Klinke JA, Johnson JA, Guirguis LM, Toth EL, Lee TK, Lewanczuk RZ, Majumdar SR: Underuse of aspirin in type 2 diabetes mellitus: prevalence and correlates of therapy in rural Canada. Clin Ther 2004, 26:439-46.

16. Cull CA, Neil HA, Holman RR: Changing aspirin use in patients with Type 2 diabetes in the UKPDS. Diabet Med 2004, 2I:|368-7|. 
17. Rolka DB, Fagot-Campagna A, Narayan KM: Aspirin use among adults with diabetes: estimates from the Third National Health and Nutrition Examination Survey. Diabetes Care 200I, 24:|97-20|.

18. Morimoto T, Fukui T, Lee TH, Matsui K: Application of U.S. guidelines in other countries: aspirin for the primary prevention of cardiovascular events in Japan. Am J Med 2004, I 1 7:459-68

19. Lamberts H, Wood M: Clasificación Internacional de la Atención Primaria CIAP-2. Clasificación de razones de consulta. Barcelona, Masson/SG; 1990.

20. Friedewald WT, Levy RJ, Frederickson DS: Estimation of the concentration of low-density lipoproteins cholesterol in plasma without use of the preparative ultracentrifuge. Clin Chem 1972, I 8:499-502.

21. Grupo de Trabajo Diabetes mellitus: Diabetes mellitus y riesgo cardiovascular. Recomendaciones del Grupo de Trabajo Diabetes Mellitus y Enfermedad Cardiovascular de la Sociedad Española de Diabetes. Clin Invest Arterioscl 2004, I:74-8.

22. Bueno $\mathrm{H}$ : Infrautilización del ácido acetilsalicílico en la prevención cardiovascular del paciente con diabetes mellitus. Med Clin (Barc) 2004, I 22: I0I-3.

23. Mahon J, Steel K, Feagan BG, Laupacis A, Pederson LL: Use of acetylsalicylic acid by physicians and in the community. CMAJ 199I, I45: I 107-16.

24. Hennekens $\mathrm{CH}$, Knatterud GL, Pfeffer MA: Use of aspirin to reduce risks of cardiovascular disease in patients with diabetes: clinical and research challenges. Diabetes Care 2004, 27:2752-4

25. Wenberg J: Dealing with medical practice variation: aproposal for action. Health Aff I 984, 3:6-31.

26. Haffner SM, Lehto S, Ronnemaa T, Pyorala K, Laakso M: Mortality from coronary heart disease in subjects with type 2 diabetes and in nondiabetic subjects with and without prior myocardial infarction. N Engl J Med 1998, 339:229-34.

27. Krentz AJ: Lipoprotein abnormalities and their consequences for patients with type 2 diabetes. Diabetes Obes Metab 2003 5(Suppl I):S19-27.

28. de la Calle H, Costa A, Díez-Espino J, Franch J, Goday A: Evaluación del cumplimiento de los objetivos de control metabólico de la diabetes mellitus tipo 2. Estudio TranSTAR. Med Clin (Barc) 2003, I 20:446-50.

29. Sacco M, Pellegrini F, Roncaglioni MC, Avanzini F, Tognoni G, Nicolucci A, on behalf of the PPP Collaborative Group: Primary prevention of cardiovascular events with low-dose aspirin and vitamin $E$ in type 2 diabetic patients: results of the Primary Prevention Project (PPP) trial. Diabetes Care 2003, 26:3264-72

30. Ceriello A, Motz E: Prevention of vascular events in diabetes mellitus: which "antithrombotic" therapy? Diabetologia 1996 39:1405-6.

3I. Ezekowitz JA, Straus SE, Majumdar SR, McAlister FA: Stroke: strategies for primary prevention. Am Fam Physician 2003, 68:2379-86.

32. Colwell JA: Antiplatelet agents for the prevention of cardiovascular disease in diabetes mellitus. Am J Cardiovasc Drugs 2004, 4:87-106.

33. Sackett D, Rosenberg W, Gray J, Haynes Rb, Richardson WS: Evidence based medicine: what it is and what it isn't. BM] 1996, 3| 2:7|-2.

34. Ezekowitz JA, Straus SE, Majumdar SR, McAlister FA: Stroke: strategies for primary prevention. Am Fam Physician 2003, 68:2379-86.

35. Tendera M, Wojakowski W: Role of antiplatelet drugs in the prevention of cardiovascular events. Thromb Res 2003, I I 0:355-9.

36. Candido R, Srivastava P, Cooper ME, Burrell LM: Diabetes mellitus: a cardiovascular disease. Curr Opin Investig Drugs 2003, 4:1088-94.

37. Colwell JA, Nesto RW: The platelet in diabetes: focus on prevention of ischemic events. Diabetes Care 2003, 26:2।8I-8.

38. Nowak SN, Jaber LA: Aspirin dose for prevention of cardiovascular disease in diabetics. Ann Pharmacother 2003, 37:||16-21.

\section{Pre-publication history}

The pre-publication history for this paper can be accessed here:

http://www.biomedcentral.com/1471-2296/8/60/prepub
Publish with Bio Med Central and every scientist can read your work free of charge

"BioMed Central will be the most significant development for disseminating the results of biomedical research in our lifetime. "

Sir Paul Nurse, Cancer Research UK

Your research papers will be:

- available free of charge to the entire biomedical community

- peer reviewed and published immediately upon acceptance

- cited in PubMed and archived on PubMed Central

- yours - you keep the copyright

Submit your manuscript here:

http://www.biomedcentral.com/info/publishing_adv.asp
BioMedcentral 